\title{
Smokers are unaware of the filter vents now on most cigarettes: results of a national survey
}

Lynn T Kozlowski, Marvin E Goldberg, Berwood A Yost, Frank M Ahern, Keith R Aronson, Christine T Sweeney

\begin{abstract}
Objective-To evaluate awareness and knowledge of cigarette filter ventilation in a national probability sample of smokers of Ultra-light, Light, and regular cigarettes.
\end{abstract}

Design-Random-digit-dialling and computer-assisted telephone interviewing was used on a probability sample of daily cigarette smokers (ages 18 and above).

Subjects and setting-218 Smokers of Ultra-light cigarettes, 360 smokers of Light cigarettes, and 210 smokers of Regular cigarettes living in the continental United States.

Main outcome measures-Percentage of respondents indicating knowledge of the presence of filter vents and the consequences of behavioural blocking of vents.

Results-Many smokers had not heard about or seen the filter holes: $43 \%$ (95\% CI = 36 to $50 \%$ ) of smokers of Ultra-lights, $39 \%(95 \% \mathrm{CI}=34$ to $44 \%)$ of smokers of Lights, and $47 \%(95 \% \mathrm{CI}=40$ to $54 \%)$ of smokers of Regulars. About two in three smokers either did not know of the existence of rings of small holes on the filters of some cigarettes, or did not know that blocking increases tar yields: $69 \%$ $(95 \% \mathrm{CI}=63$ to $75 \%)$ of Ultra-lights, $66 \%$ $(95 \% \mathrm{CI}=61$ to $71 \%)$ of Lights, and $69 \%$ (95\% CI $=63$ to $75 \%$ ) of Regulars.

Conclusions-Smokers are generally unaware of the presence and function of filter vents-a major design feature subject to behavioural blocking by smokers and now present on most cigarettes in the United States. Smokers and policy-makers need to be informed about the presence of filter vents and how vent blocking increases tar and nicotine yields from ostensibly very low-yield cigarettes.

(Tobacco Control 1996;5:265-270)

Keywords: cigarette filter ventilation; filter vent blocking; awareness survey.

\section{Introduction}

Low-tar, "Light" and "Ultra-light" cigarettes are promoted by the cigarette industry to help keep health-conscious smokers smoking. ${ }^{1-5}$ Filter ventilation, whereby each puff taken by a smoking machine is diluted from a few percentage points up to about $90 \%$ with air, is a major manufacturing technique for making $c r$ modern "low-yield" cigarettes. ${ }^{67}$ Air dilution + reduces standard Federal Trade Commission of (FTC) tar yields - the greater the dilution, the 0 lower the standard yields of tar, nicotine, and carbon monoxide (CO).$^{89}$ Filter ventilation $\square$ contributes to what is described within the cigarette industry as "elasticity", whereby a $\frac{\mathbb{\Phi}}{3}$ cigarette gives lower tar and nicotine yields when tested by the FTC method than when smoked by humans. ${ }^{10}$ "Elasticity" is also $\varnothing$ known as "compensatory smoking" and is a major cause of consumers being misled by the current system of testing cigarettes. ${ }^{10-12}$

Although official FTC smoking machines do not interfere with filter ventilation, human $\frac{\otimes}{\Phi}$ smokers can and do block filter vents with their $\varrho$ lips or fingers, thereby compromising $\overrightarrow{\overrightarrow{0}}$ ventilation function. ${ }^{1314}$ At the extreme, some smokers report carrying rolls of tape to cover vents, possibly indicating substantial lack of knowledge of the effects of blocking on tar and 0 nicotine exposures. Kozlowski et al ${ }^{1415}$ found that most smokers who block vents are either not aware of doing the blocking, or not aware of its consequences for tar and nicotine $\overrightarrow{\vec{D}}$ exposures. In eight studies, ${ }^{14-21}$ the prevalence $\frac{O}{\sigma}$ of extreme vent blocking (most vents were 3 blocked) ranged from 1 per 1000 to 210 per $\delta$ 1000 (median $=19 \%$ ) and the prevalence of "at least some blocking" ranged from 61 per을 1000 to 580 per 1000 (median $=50 \%$ ).

Rickert et $a l^{2}$ demonstrated that the standard yields of tar, nicotine, and carbon $N$ monoxide more than doubled when $50 \%$ of the vent holes of 28 brands of ventilated-filter ciga- $N$ rettes were blocked with tape. Using 1-mg tar ${ }^{\omega}$ cigarettes blocked to different degrees by the experimenter, Zacny and colleagues ${ }^{23}$ showed $\stackrel{0}{\circ}$ that full blockage led to a doubling of carbon $\stackrel{\Phi}{\longrightarrow}$ monoxide intake. In a recent study, Kozlowski et $a l^{24}$ showed that it was not difficult for smok-o ers to block vents on 1-mg tar cigarettes with their lips and, in doing so, double carbon mon- $\frac{\mathbb{Q}}{\varrho}$ oxide intake.

In $1995,59.7 \%$ of the cigarettes sold in the United States were in the low-tar, less than $16 \mathrm{mg}$ FTC tar category (approximate Light range $[7-15 \mathrm{mg}$ tar $]=47.8 \%$, approximate Ultra-light range [ $6 \mathrm{mg}$ tar or less] $=11.9 \%$ of the market). ${ }^{25}$ Most attention has been focused on issues related to filter ventilation in Light 
Table 1 Sample characteristics by brand category

\begin{tabular}{llll}
\hline Variables & $\begin{array}{l}\text { Ultra-light } \\
(n=218)\end{array}$ & $\begin{array}{l}\text { Light } \\
(n=360)\end{array}$ & $\begin{array}{l}\text { Regular } \\
(n=210)\end{array}$ \\
\hline (1) Female (\%) & 70 & 62 & 49 \\
(2) White (\%) & 97 & 89 & 83 \\
$\begin{array}{l}\text { (3) African-American (\%) } \\
\text { (4) Hispanic (\%) }\end{array}$ & 1 & 5 & 9 \\
(5) High school degree or more (\%) & 1 & 4 & 8 \\
(6) Average age (mean (SD)) (years) & 55 & 49 & 45 \\
(7) Cigarettes per day (mean (SD)) & $47(14)_{\mathrm{a}}$ & $40(13)_{\mathrm{b}}$ & $41(15)_{\mathrm{b}}$ \\
\hline
\end{tabular}

There were significant linear trends for variables in rows $1-5(\mathrm{P}<0.05)$.

Within row 6 , different subscripts indicate $P<0.05$ by Bonferonni $t$ 's.

Within row 7 , there was a marginal linear trend $(P=0.08)$.

and Ultra-light cigarettes, under the assumption that Regular, full-flavour cigarettes (>15 mg tar) do not have ventilated filters. A recent reading of a deposition given by a senior scientist at RJ Reynolds Tobacco Company posted on the Internet, ${ }^{26}$ however, disclosed that Winston ("Reds," full-flavour) have had ventilated filters since the early 1980s. Visual inspection with a magnifying glass of nine bestselling full-flavour brands (Camel, Basic, Benson \& Hedges, GPC, Kool, Marlboro, Newport, Winston, and Salem) showed that four (Marlboro, Winston, Camel, and Benson $\&$ Hedges) all have detectable vent holes on the filters. We do not know what percentage of the Marlboro $30 \%$ or the Winston $5.8 \%$ market share $^{25}$ is due to Regular cigarettes, but if it were half, that alone would indicate that at least $75 \%$ of current American cigarettes have filter vents $(59.7 \%$ for under $16 \mathrm{mg}$ tar $+17.9 \%$ for Marlboro and Winston Regulars $=77.6 \%$ ); if we assumed that only a third of the Marlboros, Winstons, Camels, and Benson \& Hedges were Regular versions, at least $73.7 \%$ of cigarettes may have ventilated filters.

The only published data on smokers' knowledge of vents and their function have been based on small, convenience samples. The purpose of this study was to obtain data on a substantial probability sample of smokers in the United States. To what extent are smokers aware of the existence of filter vents on cigarettes? Do smokers understand the function of filter vents (what happens if vents are blocked)?

\section{Methods}

STUDY DESIGN

We used random-digit-dialling and computerassisted telephone interviewing ${ }^{27}$ to conduct 15-minute interviews on a probability sample of daily smokers (aged 18 and above) who live in the continental United States. The last-birthday method was used to select respondents within each household. ${ }^{28}$ This research protocol was approved by the Research Compliance Office of Penn Sate University. Oversampling was done for smokers of Ultra-lights, and we limited our sample of Regular smokers (because at the time of the survey we did not yet know that any Regular cigarettes had vented filters). The sample is random within brand category. The survey focused on questions about the percep- tion of Light and Ultra-light cigarettes. The average duration of interviews was 13.3 (SD 3.5) minutes. As many as 20 callbacks were made. The response rate of $63 \%$, according to the Council of American Survey Research formula, ${ }^{29}$ was at an acceptable, commonly achieved level. The cooperation rate (completed interviews/all contacted capable of being interviewed) was $73 \%$.

\section{PARTICIPANTS}

The participants were self-reported daily smokers (aged 18 and above) of Ultra-light cigarettes $(\mathrm{n}=218), \quad$ Light cigarettes $(n=360)$, and Regular cigarettes $(n=210)$. The screening question was: "Is your brand an Ultra-light, Light, or Regular cigarette?" Pilot rèsearch showed that the phrasing of this question dealt with a possible confusion between the term "regular" referring to short cigarettes vs "regular, full-flavour cigarettes." The term "full-flavour" was found unnecessary in the context of this question. In response to a question about how certain the respondent was about the category of his or her brand, $82 \%$ of the Ultra-light smokers were "very certain" and $13 \%$ "somewhat certain"; $75 \%$ of the Light smokers were "very certain" and 20\% "somewhat certain"; and $87 \%$ of the Regular smokers were "very certain" and $8 \%$ "somewhat certain". Table 1 details participant demographic information.

\section{KEY SURVEY QUESTIONS}

The survey was designed to have open-ended and fixed-response questions on filter vents. The open-ended question, placed early in the survey, did not direct respondents to specific features of filters:

- "What makes the filters on Light [or Ultra-light, if smokers of Ultra-lights] cigarettes different than the filters on Regular cigarettes?" (Asked open-ended, with up to five probes, "Anything else?").

The key fixed-response question concerning filter ventilation was:

- "Have you ever seen or heard that one or more rings of small holes are on the filters of some cigarettes?" (Response options: yes; no; don't know).

Participants who responded "yes" were also asked the following:

- "How do you know about these holes?" (Responses were classified by the interviewer into the following pre-specified categories: saw them; read about them in the news or magazine; someone told me; saw a television advertisement about them; saw or heard a news report about them; other; don't know; refused.)

- "Did you ever try to block the filter holes on cigarettes?"(Response options: yes; no; don't know.)

- "How did you block the filter holes?" (Asked open-ended.)

- "At the present time do you block holes when you smoke?" (Response options: yes; no; don't know.)

- "Do you think that blocking filter holes would make a cigarette taste stronger, 
Table 2 Lack of knowledge of vents and function by brand category

\begin{tabular}{|c|c|c|c|c|c|c|}
\hline \multirow[b]{2}{*}{ Response } & \multicolumn{2}{|c|}{$\begin{array}{l}\text { Ultra-light } \\
(n=218)\end{array}$} & \multicolumn{2}{|c|}{ Light $(n=360)$} & \multicolumn{2}{|c|}{$\begin{array}{l}\text { Regular } \\
(n=210)\end{array}$} \\
\hline & $(\%)$ & $95 \% C I$ & $(\%)$ & $95 \% C I$ & $(\%)$ & $95 \% C I$ \\
\hline $\begin{array}{l}\text { Not reporting vents or holes as } \\
\text { "different" feature on the filters } \\
\text { of Lights (open-ended) }\end{array}$ & 92 & $88-96$ & 95 & $93-97$ & 99 & $98-100$ \\
\hline $\begin{array}{l}\text { Not heard about or seen the rings } \\
\text { of small holes on the filters of } \\
\text { some cigarettes (fixed-response) }\end{array}$ & 43 & $36-50$ & 39 & $34-44$ & 47 & $40-54$ \\
\hline $\begin{array}{l}\text { Unaware of vents or not } \\
\text { understand vent blocking } \\
\text { increases tar exposure }\end{array}$ & 69 & $63-75$ & 66 & $61-71$ & 69 & $63-75$ \\
\hline
\end{tabular}

$\mathrm{CI}=$ confidence interval.

* Significant linear trend $(\mathrm{P}<0.05)$ as a function of brand category.

Table 3 Lack of knowledge of vent function for those reporting awareness of existence of filter vents by brand category

\begin{tabular}{|c|c|c|c|c|c|c|}
\hline \multirow[b]{2}{*}{ Response } & \multicolumn{2}{|c|}{ Ultra-light $(n=125)$} & \multicolumn{2}{|c|}{ Light $(n=221)$} & \multicolumn{2}{|c|}{ Regular $(n=112)$} \\
\hline & $(\%)$ & $95 \% C I$ & $(\%)$ & $95 \% C I$ & $(\%)$ & $95 \% C I$ \\
\hline $\begin{array}{l}\text { Unaware that taste is stronger } \\
\text { with blocking of vents } \\
\text { Unaware that tar increases with }\end{array}$ & 31 & $23-39$ & 33 & $27-39$ & 24 & $16-32$ \\
\hline $\begin{array}{l}\text { blocking of vents } \\
\text { Unaware that nicotine increases }\end{array}$ & 46 & $38-54$ & $44^{\star}$ & $38-50$ & 42 & $33-51$ \\
\hline with blocking of vents & 46 & $38-54$ & $43^{\star}$ & $36-50$ & 40 & $31-49$ \\
\hline
\end{tabular}

$\mathrm{CI}=$ confidence interval.

* One refusal reduced $\mathrm{n}$ by one. Within brand category, respondents were more aware that taste increases than either tar or nicotine increases $(\mathrm{P}<0.01$, paired $t$ tests).

milder, or have no effect on the taste?" (Response options: a lot stronger; moderately stronger; a little stronger; no effect; a little milder; moderately milder; a lot milder; don't know);

- "Do you think that blocking filter holes would increase, decrease, or have no effect on the tar a smoker gets from these cigarettes?" (Response options: greatly increase; moderately increase; slightly increase; no effect; slightly decrease; moderately decrease; greatly decrease; don't know)

- "Do you think that blocking filter holes would increase, decrease, or have no effect on the nicotine a smoker gets from these cigarettes?" (Response options: greatly increase; moderately increase; slightly increase; no effect; slightly decrease; moderately decrease; greatly decrease; don't know).

\section{ANALYSES}

Responses to the last three questions were recoded in the following manner: those who responded "no effect", "a little milder", "moderately milder", "a lot milder", or "don't know", to the question regarding the effect of blocking on cigarette taste, for example, were classified as being "unaware". Similarly, those participants who responded "no effect", "slightly decrease", "moderately decrease", "greatly decrease", or "don't know" to the questions regarding the effect of blocking on tar and nicotine yields were also classified as being "unaware".

Response percentages were calculated within each brand category, with $95 \%$ confidence intervals (CIs). Between-group tests were done using analyses of variance with Bonferroni adjustments for comparisons or with $\chi^{2}$ analyses. ${ }^{30}$ Within-group comparisons were done with paired $t$ tests. Multiple regression analyses (ordinary least squares, linear probability model) were used to explore $O$ predictors of knowledge of vents (scored $1=$ yes, 2 = no, don't know) and knowledge that blocking increased tar intake (scored $1=$ increase tar, $2=$ no effect, decrease tar, don't know). Brand category was included in the regression analyses to adjust for group membership effects. All probability values are for two-sided tests.

\section{Results}

Are smokers aware of the existence of filter vents on low-tar brands?

On the fixed-response question on knowledge of the presence of filter vents, $39 \%-47 \%$ of the respondents reported not having seen or heard about vents. Table 2 gives a summary with $\rightarrow$ $95 \%$ CIs. On the open-ended question, under $10 \%$ of any of the three categories of smokers report that vents or more vents are a special feature of Light or Ultra-light cigarettes, indicating that most smokers are unaware of vents (table 2). When those who reported knowing of the existence of filter holes were asked how they knew about the holes, most said that they had "seen them" (UL $=84 \%$, $\mathrm{L}=83 \%, \mathrm{R}=83 \%$ ), followed by "someone ? told me" (UL $=9 \%, \mathrm{~L}=7 \%, \mathrm{R}=8 \%$ ), followed by "read about them in the news or magazine" (UL $=3 \%, \mathrm{~L}=5 \%, \mathrm{R}=4 \%$ ), followed by "saw a television advertisement about them" (UL= $3 \%, \mathrm{~L}=3 \%, \mathrm{R}=3 \%$ ), followed by "saw or heard a news report about them" (UL $=1 \%, \mathrm{~L}=1 \%, \mathrm{R}=1 \%)$.

Do smokers understand what happens if vents are blocked?

Of those who knew about the existence of filter holes, most were aware that blocking vents would increase tar exposure (table 3 ). Within each brand category, more smokers were aware that blocking would increase taste than were aware that blocking would increase tar and nicotine $(\mathrm{P}<0.01)$.

How many smokers either are unaware of vents or unaware of consequences of blocking?

A general index of unawareness about vents $\frac{D}{O}$ and vent function was created. Adding (a) those who are unaware of filter vents (using the $N$ fixed-response question) to (b) those who $N$ know about vents but who are unaware that blocking would increase tar exposure, gives (c) lack of knowledge about filter ventilation, which is found in two-thirds or more of smokers (table 2).

To what extent do smokers report vent-blocking with fingers, lips, or tape?

Ever blocking. When those who knew about filter vents were asked if they had ever blocked 0 vents (intentionally or unintentionally), $10 \%$ of 8 Ultra-light smokers, $10 \%$ of Light smokers, and $18 \%$ of Regular smokers said they had. When asked how they had blocked vents, most said "with fingers" (UL $=43 \%, \mathrm{~L}=41 \%$, $\mathrm{R}=51 \%$ ), "with tape" (UL $=36 \%, \mathrm{~L}=32 \%$, $R=16 \%$ ), or "with lips" (UL $=7 \%, L=3 \%$, 
$\mathrm{R}=0 \%$ ). Twenty-seven per cent of Regular and $19 \%$ of Light smokers said they had cut the filters in two at the vents as a way to defeat ventilation.

Current blocking. Only 1-2\% who had heard of vents reported vent blocking at the present time.

Additional analyses. Analyses were performed to assess demographic differences across the brand categories (table 1 for results). Exploratory multiple regression analysis $\left(R^{2}=0.06\right.$, $\mathrm{df}=782, \quad \mathrm{P}<0.0001)$ indicated that older smokers (standardised $\quad \beta=0.15, \quad 95 \%$ $\mathrm{CI}=0.08$ to 0.22$)$, males $(0.14,95 \%$ $\mathrm{CI}=0.07$ to 0.21 , those smoking more cigarettes each day $(0.10,95 \% \mathrm{CI}=0.03$ to $0.17)$, and those smoking Lighter brands $(0.07,95 \% \mathrm{CI}=0$ to 0.14$)$ were more likely to know about the presence of filter vents. Education was not a statistically significant predictor. Using the 458 respondents who knew about vents, predictors of knowledge that vent blocking increases tar intake were explored. Men were more likely to report that blocking increased tar (standardised $\beta=0.12,95 \%$ $\mathrm{CI}=0.03$ to $0.21, R^{2}=0.015$ ); sex, age, education, and brand category were not statistically significant predictors.

\section{Discussion}

One may dispute the national representativeness of our sample, which would not have included those who did not have telephones, ${ }^{31}$ however, the study does provide a substantial, national probability sample of self-proclaimed daily smokers (age 18 and over) of Ultra-light, Light, and Regular cigarettes. The finding that lower-yield cigarettes are predominantly smoked by whites and those with higher education has been found in other surveys. ${ }^{32}$ Other survey procedures might lead to somewhat different prevalence estimates, but we think that a serious problem has been persuasively identified.

Our findings indicate substantial unawareness on the part of cigarette smokers of a key design feature of modern cigarettes. Sixty-nine per cent of Ultra-light smokers, $66 \%$ of Light smokers, and $69 \%$ of Regular smokers are either unaware of filter vents or do not know that vent blocking increases tar yields. Direct, fixed-response questions on filter holes are leading and likely to be subject to a kind of "yea-saying bias": people may be more likely to admit to knowing a fact rather than to admit ignorance of a fact presumed by the asking of the question. This bias is, however, conservative, leading to an overestimate rather than an underestimate of knowledge of vents. It should also be noted that the fixed-response questions asked about knowledge of vents on some cigarettes. Some of those individuals who knew about vents on some cigarettes may still have been unaware of them on other cigarettes, even on their own brand.

Although from some perspectives our sample sizes may seem relatively small for a national survey, our oversampling did provide us with an unusually large sample of Ultra-light smokers which, for example, was 15 times larger (218 vs 14 ) than that provided in a major, national study ${ }^{4}$ on smoker perceptions not employing oversampling for smokers of Ultra-lights.

We were not aware that Regular cigarettes had become ventilated until reading the deposition by Townsend. ${ }^{26}$ Although the openended question may be impaired because it asks about features that make the filters "different" on Light cigarettes, it is by no means invalidated because (a) many Regular cigarettes do not have vents, (b) we are unlikely to be alone in the belief that Regulars are not ventilated, and (c) it would still be correct to say that Lights have "more vents". ${ }^{9}$ A product that is $90 \%$ ventilated should produce a much more noticeable air dilution effect than one that is only $10 \%$ ventilated.

The cigarette industry has acknowledged that vent blocking can happen, ${ }^{33}$ but disputes the prevalence of the problem. The best overall estimate of the prevalence of the problem indicates that a median of $50 \%$ of smokers are blocking at least some of the filter vents. We think, however, that even if the lowest reported prevalence level for some blocking (that is, $6 \%$, see the Introduction) were accepted, this level of blocking, coupled with the large number of unaware smokers, justifies the need for smokers to be informed about the problem of vent blocking, and for manufacturers to mark clearly the presence of vents on filters. It should be stressed that this study was not intended or designed to provide good estimates of the prevalence of vent blocking. Because smokers are often not aware of vent blocking, such estimates could only come from studies involving analyses of spent filters, biochemical indicators of exposure to smoke, and, ideally, observation of smokers. Interestingly, our pattern of results replicates the finding that smokers are much more likely to report that they used to block than to report that they do so at present. ${ }^{14}$ It appears that smokers are not a good judge of current blocking behaviour and that much blocking takes place outside of awareness. ${ }^{14}$

Cigarette manufacturers not only fail to identify the presence of vents, but they also make much filter ventilation "invisible", ${ }^{26}$ even though they are able to ventilate filters either "visibly" or "invisibly". For a design feature so subject to behavioural subversion to be kept secret from smokers is comparable to keeping secret from car drivers the existence of the speedometer or the safety belt. At least one cigarette manufacturer has discussed marking the presence of vents on filters, but to our knowledge this manufacturer has not yet decided to mark the presence of vents on all of its ventilated-filter brands. $^{26}$ It has been suggested that filters should be marked with both a visual and tactile indication of the location of the vents; that is, smokers should be able to both see and feel where the vents are. ${ }^{34}$ The finding above (table 3), that most smokers who know about vents also understand that blocking increases tar and nicotine exposure, supports the importance of educating smokers about the presence of vents. Our multivariate analyses of predictors of knowledge might be 
used to develop targeted information campaigns, but the factors (age, sex, heaviness of smoking, education, brand category) together or separately were not very strong predictors of knowledge, indicating the need for widespread distribution of information about vents and vent function.

All smokers need to be warned of the presence and function of filter vents. Such a warning can be used to motivate smokers to start the important task of giving up smoking completely. The Marlboro and Winston brand families together accounted for nearly $36 \%$ of the cigarette market in $1995 .^{25}$ It is instructive to see how similar these Regular and Light brands are: about $16 \mathrm{mg}$ tar for Marlboro, $17 \mathrm{mg}$ tar for Winston and $10 \mathrm{mg}$ tar for each of their Light varieties. By taking only three or four extra puffs on a Light, $6 \mathrm{mg}$ of extra tar could be ingested by a smoker-even if vent holes are not blocked on the Light (cf..$^{35}$ ). The large amount of research on compensatory smoking in self-selected smokers of various strength cigarettes generally does not find differences in average smoke exposure between smokers of Light and Regular cigarettes (for example, refs 1 and 38). With vent holes blocked, just one extra puff might lead to full compensation. Because of the overall similarities between Light and Regular cigarettes, full compensation is possible with a Light cigarette, even if the vents on the Lights are not blocked $\left(\mathrm{cf}^{39}\right)$. With compensating changes in inhalation volumes, the small differences between Lights and Regulars can also be eliminated. Therefore, warning smokers of Lights to not block filter vents probably does not offer protection against the risks of smoking Light cigarettes.

Warnings about vent blocking on $1 \mathrm{mg}$ tar cigarettes may lead to reduced smoke exposure from these Ultra-light cigarettes: behavioural vent-blocking can double carbon monoxide exposures on $1 \mathrm{mg}$ tar cigarettes. ${ }^{24}$ Whether blocking will similarly affect yields on other Ultra-light brands is unknown. In studies that involved little or no vent blocking, $1 \mathrm{mg}$ tar, $0.1 \mathrm{mg}$ nicotine cigarettes delivered substantially less nicotine than did regular cigarettes. ${ }^{39-41}$

Filter vents on Light and Regular cigarettes may well be an important example of a design feature that can influence standard FTC tar and nicotine yields but may have no meaningful effect on human smoke exposures. The standard FTC method by which cigarettes are currently called Light or Ultra-light is in urgent need of change. ${ }^{7-11}$

Systems essentially equivalent to the FTC method are widely used around the world. Twenty-two countries-including many in the European Union-now have legislation specifying a maximum tar yield of cigarettes; 12 countries specify maximum nicotine yields, and one country, Finland, specifies a maximum carbon monoxide yield. ${ }^{42}$ Twentynine more countries now have proposals for restricting tar deliveries. ${ }^{42}$ Ventilated filters are being promoted as a way for the cigarette industry to comply with these standards. ${ }^{42}$ The use of filter ventilation as a yield-reduction technique should be evaluated worldwide, especially wherever standard yields appear to be declining.

This study was supported by subcontract number TS-104-11/11 under the cooperative agreement between the Association of Teachers of Preventive Medicine and the US Centers for Disease Control and Prevention. Thanks for helpful comments go to Janine L Pillitteri and Gary A Giovino.

1 Gerstein DR, Levison PK. Reduced tar and nicotine cigarettes: Smoking behavior and health. In: Committee on Substance Abuse and Habitual Behavior, Commission on Behavioral and Social Sciences and Education, NRC. Washington, DC: National Academy Press, 1982.

2 Davis RM. Current trends in cigarette advertising and marketing. N Engl F Med 1987;316:725-32.

3 Cohen JB. Research and policy issues in Ringold and Calfee's treatment of cigarette health claims. $\mathcal{F}$ Public Policy Marketing 1992;11:82-6.

4 Cohen JB. Smokers' knowledge and understanding of advertised tar numbers: Health policy implications. $A m \mathcal{F}$ Public Health 1996;86:18-24.

5 Slade J, Connolly GN, Davis RM, et al. Report of the Policy Research Study Group on tobacco products. Tobacco Control 1992;1 (suppl):S4-9.

6 Kozlowski LT. Perceiving the risks of low-yield ventilatedfilter cigarettes: The problem of hole-blocking. In: Covello VT, Flamm WG, Rodericks JV, Tardiff RG, eds. Proceedings of the international workshop on the analysis of actual versus perceived risks. New York, NY: Plenum, 1983:175-82.

7 Henningfield JE, Kozlowski LT, Benowitz NL. A proposal to develop meaningful labeling for cigarettes. $\mathfrak{f} A M A$ 1994 272:312-14.

8 Federal Trade Commission. Tar, nicotine, and carbon monoxide of the smoke of 993 varieties of domestic cigarettes. Washington DC: Federal Trade Commission, 1994.

9 Parker JA, Montgomery RT. Design criteria for ventilated filters. Beitr Tabakforsch Int 1979;10:1-6.

10 US Department of Health and Human Services. Food and Drug Administration [Docket No 95N-0253]] Analysis regarding The Food and Drug Administration's jurisdiction over nicotine-containing cigarettes and smokeless tobacco products. Federal Register 1995;60(155):41453787.

11 Jenks S. Low-tar cigarettes pose hidden health threat, pane says. $\mathcal{F}$ Natl Cancer Inst 1995;87:15-16.

12 Kozlowski LT, Pillitteri JL. Compensation for nicotine by smokers of lower-yield cigarettes. In: The FTC method for determining tar, nicotine, and carbon monoxide yields of US cigarettes: report of the NCI Expert Committee. Bethesda MD: National Cancer Institute, US Department of Health and Human Services; 1996:161-72.

13 Kozlowski LT, Frecker RC, Khouw V, Pope M. The misuse of 'less-hazardous' cigarettes and its detection: Holeblocking of ventilated filters. Am $¥$ Public Health 1980; 70:1202-3

14 Kozlowski LT, Rickert WS, Pope MA, Robinson JC, Frecke RC. Estimating the yield to smokers of tar, nicotine, and carbon monoxide from the 'lowest yield' ventilated-filter cigarettes. $\mathrm{Br} \mathcal{F}$ Addict 1982;77:159-65.

15 Lombardo T, Davis CJ, Prue DM. When low tar cigarettes yield high tar: Cigarette filter ventilation hole blocking and its detection. Addict Behav 1983;8:67-9.

16 Robinson JC, Young JC, Rickert WS, Fey G, Kozlowski LT. A comparative study of the amount of smoke absorbed from low yield ('less hazardous') cigarettes. Part 2: Invasive measures. $B r f$ Addict 1983;78:79-87.

17 Kozlowski LT, Heatherton TF, Frecker RC, Nolte HE. Selfselected blocking of vents on low-yield cigarettes. Pharma col Biochem Behav 1989;33:815-19.

18 Kozlowski LT, Pope MA, Lux JE. Prevalence of the misuse of ultra-low-tar cigarettes by blocking filter vents. $A m$ Public Health 1988;78:694-5.

19 Zacny JP, Stitzer ML. Cigarette brand-switching: Effects on smoke exposure and smoking behavior. $\mathcal{F}$ Pharmacol Exp Ther 1988;246:619-27.

20 Hofer I, Nil R, Battig K. Ultralow-yield cigarettes and type of ventilation: The role of ventilation blocking. Pharmacol Biochem Behav 1991;40:907-14.

21 Kozlowski LT, Pillitteri JL, Sweeney CT. Misuse of "Light" cigarettes by means of vent blocking. F Substance Abuse 1994;6:333-6.

22 Rickert WS, Robinson JC, Young JC, Collishaw NE, Bray DF. A comparison of the yields of tar, nicotine, and carbon monoxide of 36 brands of Canadian cigarettes tested monoxide of 36 brands of Canadian cigarettes
under three conditions. Prev Med 1983;12:682-94.

23 Zacny JP, Stitzer ML, Yingling JE. Cigarette filter ven blocking: Effects on smoking topography and carbon 25:1245-52.

24 Kozlowski LT, Sweeney CT, Pillitteri JL. Blocking cigarette filter vents with lips more than doubles carbon monoxide intake from ultra-low tar cigarettes. Exp Clin Psychopharmacol 1996;4:1-5.

25 Maxwell JC. Marlboro dominates. Tobacco Rep 1996; 123:19-21. 
26 Townsend, D. Deposition of David Townsend, in the Circui Court, 4th Judicial Circuit, Duval County, Florida, Case No. 95-01820-CA, Division CV-C. Jean Connor, Plaintiff, vs R.J. Reynolds Tobacco Company, etc. et al., Defendants. 3 Oct 1995: 1-102. URL: <http://www.gate.net/ icannon/documents/townsend.txt>

27 Groves RM, Biemer PP, Lyberg LE, Massey JT, Nicholls WL, Wakesberg J. Telephone survey methodology. New York, VY: John Wiley, 1988.

28 Hagan D, Collier CM. Must respondent selection procedures for telephone surveys be invasive? Public Opinion $Q$ 1983;47:547-56.

29 Council of American Survey Research Organizations (CASRO). Report of the CASRO Completion Rates Task Force. New York, NY: Audits \& Survey Co., 1982.

30 Snedecor GW, Cochran WG. Statistical methods, 7th ed. Ames, Iowa: Iowa State University Press, 1980.

31 Thornberry $\mathrm{O}$, Massey JT. Trends in telephone coverage across time and subgroups. In: Groves RM et al, eds.
Telephone survey methodology. New York, NY: Wiley, 1988:25-50.

32 Giovino GA, Tomar SL, Reddy MN, et al. Attitudes, knowledge, and beliefs about low-yield cigarettes among adolescents and adults. In The FTC method for determining tar nicotine, and carbon monoxide yields of US cigarettes: report of the NCI Expert Committee Bethesda, Maryland: National Cancer Institute, US Department of Health and Human Services, 1996:39-57.

33 Comments of Brown \& Williamson Tobacco Corporation, Liggett Group Inc., Lorillard Tobacco Company, Philip Morris Incorporated, RI Reynolds Tobacco Company, Tobacco Institute Inc. before the US Food and Drug
Administration (FDA). Regulations restricting the sale and distribution of cigarettes and smokeless tobacco products to protect children and adolescents; proposed rule, analysis regardin FDA's jurisdiction over nicotine-containing cigarettes and smokeless tobacco products. Docket Nos 95N-0253, 95N0253J, 11 August 1993 .

34 Kozlowski LT, Sweeney CT. Low-yield, light, and ultra-light cigarettes: Let's understand the product before we promote. In: Goldberg ME, Fishbein M, Middlestadt $S$ eds. Social marketing: theoretical and practical perspectives. New York, NY: Erlbaum. In press.

35 Kozlowski LT, Rickert WS, Robinson J, Grunberg NE. Have tar and nicotine yields of cigarettes changed? Science 1980;209:1550-1.

36 Kozlowski LT. Tar and nicotine delivery of cigarettes: What a difference a puff makes. $7 A M A 1981 ; 245: 158-9$.

37 Gori GB, Lynch CJ. Smoker intake from cigarettes in the $1 \mathrm{mg}$ Federal Trade Commission tar class. Regul Toxicol Pharmacol 1983;3:110-20.

38 Maron DJ, Fortmann SP. Nicotine yield and measures of cigarette smoke exposure in a large population: Are loweryield cigarettes safer? Am $\mathcal{F}$ Public Health 1987;77:546-9.

39 Benowitz NE, Jacob P, Yu L. Reduced tar, nicotine, and carbon monoxide exposure while smoking ultra-low but not low-yield cigarettes. $¥ A M A 1986 ; 256: 241-6$.

40 West RJ, Russell MAH, Jarvis MJ, Feyerabend C. Does switching to an ultra-low nicotine cigarette induce nicotine withdrawal effects? Psychopharmacology 1984;84:120-3.

41 Kozlowski LT. Less hazardous smoking and the pursuit of satisfaction. Am $\mathcal{F}$ Public Health 1987;77:539-41.

42 Morris P. Combined filter performance. Tobacco Rep 1996 Aug:60-2.

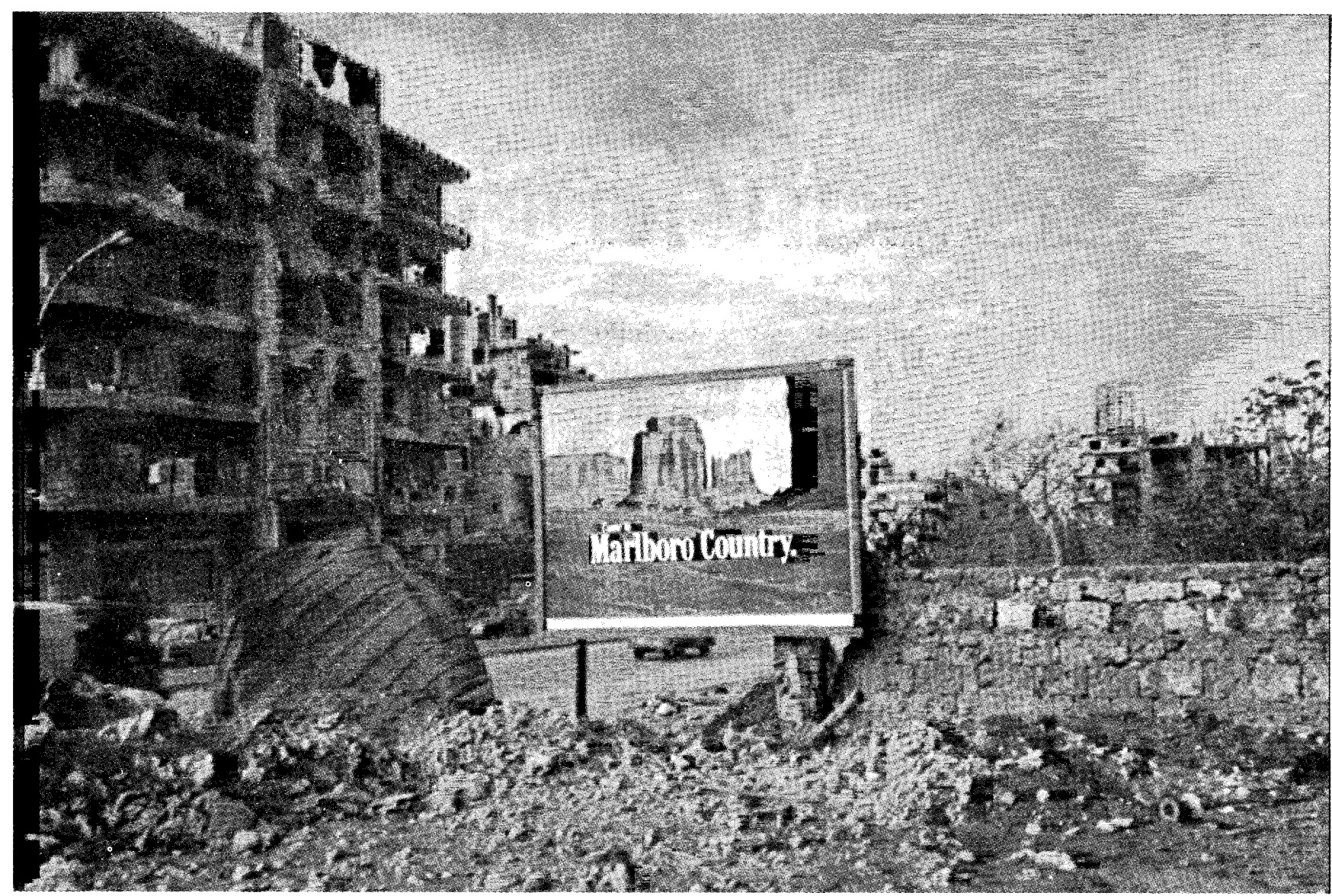

This photograph was taken by New York City artist fayce Salloum on 25 October 1992, in Beirut, Lebanon. It was on display in the summer of 1996 at American Fine Arts Company in New York City, and appeared in the November issue of Harper's Magazine. 